\title{
Review Article \\ Roles of Mesenchymal Stem Cells in Spinal Cord Injury
}

\author{
Jing Qu and Huanxiang Zhang \\ Department of Cell Biology, Jiangsu Key Laboratory of Stem Cell Research, Medical College of Soochow University, Ren Ai Road 199, \\ Suzhou Industrial Park, Suzhou 215123, China
}

Correspondence should be addressed to Huanxiang Zhang; hzhang@suda.edu.cn

Received 20 January 2017; Accepted 24 April 2017; Published 28 May 2017

Academic Editor: Luc van der Laan

Copyright (C) 2017 Jing Qu and Huanxiang Zhang. This is an open access article distributed under the Creative Commons Attribution License, which permits unrestricted use, distribution, and reproduction in any medium, provided the original work is properly cited.

Spinal cord injury (SCI) represents one of the most complicated and heterogeneous pathological processes of central nervous system (CNS) impairments, which is still beyond functional regeneration. Transplantation of mesenchymal stem cells (MSCs) has been shown to promote the repair of the injured spinal cord tissues in animal models, and therefore, there is much interest in the clinical use of these cells. However, many questions which are essential to improve the therapy effects remain unanswered. For instance, the functional roles and related molecular regulatory mechanisms of MSCs in vivo are not yet completely determined. It is important for transplanted cells to migrate into the injured tissue, to survive and undergo neural differentiation, or to play neural protection roles by various mechanisms after SCI. In this review, we will focus on some of the recent knowledge about the biological behavior and function of MSCs in SCI. Meanwhile, we highlight the function of biomaterials to direct the behavior of MSCs based on our series of work on silk fibroin biomaterials and attempt to emphasize combinational strategies such as tissue engineering for functional improvement of SCI.

\section{Introduction}

Spinal cord injury (SCI) usually results in severe neural dysfunction below the injury site. Moreover, mammals are unable to regenerate their spinal cords after injury which can lead to lifelong disability and loss of independence. After a primary damage of spinal cord tissue by a direct mechanical force, a series of secondary events involving various pathological responses accelerate the tremendous cell loss, release of cytotoxic factors, and cystic cavitation $[1,2]$. Furthermore, excessive extracellular matrices produced by activated astrocytes, called glial scarring, together with the hostile microenvironment, severely inhibit cell migration and axonal regrowth [3]. Although many experimental and clinical studies have been tested, it still lacks effective treatment until now [4-6]. The neuropathological outcome of SCI is complicated, and therefore, several challenging objectives, such as decreasing neural cell death, reducing scarring and cavitation, regaining healthy neural cells, and stimulating functional axonal regeneration, remolding the injury niche should be taken into consideration [7-11].
Numerous studies have demonstrated that stem cells might provide a source of neural cells as well as exerting neuroprotective effects after SCI. Among them, mesenchymal stem cells (MSCs) emerged as one of the most promising types of stem cells due to a favorable ethical profile and better safety [12]. The present data revealed that recovery after MSC implantation therapy is comparatively low possibly because of uncertain neural plasticity and limited capacity for the axonal regeneration of MSCs in the spinal cord $[13,14]$. The therapeutic application of MSCs in SCI is still in its infancy. It is of considerable interest as to how stem cells respond to the local environment and play functional roles in vivo, which will provide important information for improving the therapy effects and designing better therapeutic strategies.

\section{The Biological Behavior of MSCs In Vivo}

2.1. Migration of MSCs. A few points need to be taken into account to obtain more effective stem cell therapy outcomes. For instance, it is important for transplanted cells to arrive 
and migrate into the injured spinal cord tissue after intravenous infusion. It has been demonstrated that MSC homing toward injured tissue is not an efficient process; very few cells reach the injury site [15]. Some of the transplanted cells were trapped into the lung and other organs while many cells were sacrificed during the journey [16]. And only a small percentage of cells were verified to have high homing ability since the transplanted MSCs are always mixed cell populations. There are experimental data that support that MSCs possess high migratory potential and higher ability to help neural regeneration. In this case, it is believed that the insufficient number of migratory cells will partly account for the decreased number of transplanted MSCs and further decreased the cell therapy effects.

On the other hand, it is also crucial for MSCs to migrate and integrate into the host spinal cord tissue after cells are injected into a lesion, or close to a lesion area. It is not surprising that people may feel confused: Why do cells need to migrate if they are already in the lesion area? We noticed that cells would die quickly if they stayed in the injection site by in situ MSC transplantation after SCI. Actually, MSCs were observed to be migrating away from the injection site in the first 1 hour after cell transplantation. By 7 days, the cells had migrated across the injury site to form a cellular scaffold, suggesting migration toward the injury sites [17]. Also, some cells with neuronal marker expression were observed in the injured and surrounding tissues after MSC transplantation [18]. However, the engraftment potential of MSCs was low which was verified by many experiments. Indeed, MSCs delivered via injection largely remained restricted to the lesion site and were not seen to contact significant amounts of the host spinal cord tissue. The numbers of the engrafted cells are dramatically decreased after transplantation by either in situ injection or intravenous infusion [19]. It was reported that there were small numbers, even less than $0.001 \%$ to $0.002 \%$, of the transplanted MSCs left, and few functional neurons were detected after cell transplantation [20-23].

There are studies showing that the migratory and homing capacities of MSCs are closely related to their engraftment and regeneration ability. After transplantation, grafted MSCs, which possess higher migratory ability, exhibited greater survival at the periphery of the lesion. Consistently, the motor functions of the rats that had received these grafts improved significantly [21]. These data establish the fact that better recovery of damaged tissues via stem cell therapy demands sufficient recruitment of transplanted cells to the target tissue. Interestingly, it was shown that the migratory behaviors of Drosophila stem cells are closely related to their regeneration ability too. For example, hindgut stem cells of Drosophila would begin to differentiate and replace the damaged cells and tissues as long as they migrate to arrive at the right place, which is controlled by the Wnt and Hh signaling pathways $[24,25]$. The mechanisms of MSC migration and homing were extensively investigated too. Studies have demonstrated that MSCs strongly respond to inflammatory or chemotactic stimuli released from injured tissues including chemokines and various growth factors like vascular endothelial growth factor (VEGF), hepatocyte growth factor
(HGF), and SDF-1 $\alpha /$ CXCR4 axis [26, 27]. Studies indicate that MSCs with enhanced migratory ability to the lesion site following SCI enhance the antiapoptotic effects by upregulating the expression of stromal cell-derived factor-1 (SDF-1)/ CXC chemokine receptor 4 (CXCR4) axis. In one investigation, impaired expression of CXCR4 and cell engraftment was observed in populations of bone marrow MSCs [28]. Consistently, the SDF- $1 \alpha / \mathrm{CXCR} 4$ axis enhances cell migration toward injured tissues and promotes recovery after SCI by mediating bone marrow MSCs $[29,30]$. Besides, substance $\mathrm{P}$ that acts as a neurotransmitter was able to mobilize MSCs from the bone marrow and subsequently enter into the impaired tissues [31]. Granulocyte-colony-stimulating factor (G-CSF) was also known to promote mobilization of MSCs to the injured tissue [32]. Our recent study demonstrates that calcitonin gene-related peptide (CGRP) is one of the key factors that regulate the homing of transplanted MSCs to sites of SCI [21]. It looks like there are many factors that regulate the migratory behavior of MSCs. Usually, MSC cultures are initiated with a heterogeneous, poorly defined cell population. It is unknown which MSC populations are expanded and how this process affects homing capacity. There is evidence that only a small percentage of MSCs are able to migrate toward different chemotactic stimuli. We found that MSCs in varying neural differentiation states display different chemotactic responses to HGF. In addition, the phosphorylation levels of PI3K/AKT or MAPK signaling were closely related to the migration efficiency of MSCs [33]. Other authors reported that a population of $\mathrm{CD}_{3} 4^{-}$adult bone marrow-derived stem cells do not express functional CXCR4, or only a small proportion of MSCs express functionally active CXCR4 [34]. Probably, different mechanisms are involved to induce cell migration for different subpopulations of mixed MSC cultures. Precise "homing" mechanism of the transplanted cells to the lesion site is still largely unknown, which is of great interest for future study.

2.2. Differentiation of MSCs. Morphological studies showed that neuronal and oligodendroglia cell protein markers are expressed in transplanted MSCs after SCI [35]. For example, small amounts of fluorescent-tagged MSCs can be found in the blood vessels in the area of SCI where they can differentiate into NSE-positive neurons, indicating that MSCs can migrate into the injured area and differentiate into neuronlike cells. In another study, expression of $\beta$ III-tubulin at the injury site was verified indicating the potential for functional regeneration. Moreover, grafted MSC can differentiate into myelin-forming cells in the completely transected rat spinal cord [36]. However, it was reported that transplanted cells were identified adjacent to neurons and astrocytes after SCI, but no cells were seen to be labeled with any neural markers at any time [37]. Although some groups have found neuronal differentiation of MSCs in vivo, the survival number of grafted and differentiated neurons were too small to be considered to contribute to functional recovery after SCI $[38,39]$. Moreover, these cells, sometimes, do not show specific neuronal electrophysiological properties [40]. Indeed, controversial opinions are coexisted regarding the neural 
differentiation capacity of MSCs in vivo. Many experimental data support the opinion that the ability of MSCs to secrete soluble factors or vesicles rather than engrafting and transdifferentiating plays an important role in SCI repair [41-43].

2.3. Gene Therapy to Increase Nerve Regeneration of Transplanted MSCs after SCI. Efforts were made to increase the regeneration efficacy of MSC therapy for SCI. A previous study has shown that MSCs expressing the Shh transgene could increase cell survival after transplantation [44]. At day 28 after treatment, more MSCs were present in the injured tissue in the Shh-MSC group than in the MSC group. Furthermore, the transplanted cells expressing Shh exhibit enhanced functional recovery of neurological function after SCI in rats. Kumagai et al. verified that transplantation of MSCs expressing MNTS1, a multineurotrophin that binds TrkA, TrkB, and TrkC and p75NTR receptors, led to recovery of sensory function, promoting axonal growth after SCI [45]. Similarly, a series of studies indicated that NT3 or other neurotrophin gene-transfected MSCs are an effective approach to improve nerve regeneration and functional recovery after SCI [46-52].

Recently, central roles for microRNAs (miRNAs) as core regulators of gene expression during central nervous system (CNS) pathologies were revealed by many studies $[53,54]$. It has been shown that overexpression of miRNA-21 dramatically downregulates expressions of caspase-3, Fas ligand, and programmed cell death (PDCD4), improves the survival of intact motor neurons, and exerts neuroprotective effects on spinal cords against ischemia-reperfusion injury [55]. More recently, both in vitro and in vivo studies found that miR$133 \mathrm{~b}$ promotes neurite outgrowth and improve functional recovery after SCI while the detailed mechanisms need to be evaluated further [56]. The polypyrimidine tract-binding proteins (PTBPs) are one of the important RNA-binding protein family members, which are thought to be involved in cell-specific alternative splicing. PTBP1 and its brainspecific homologue polypyrimidine tract-binding protein 2 (PTBP2) regulate neural precursor cell differentiation [57]. Experimental data demonstrated that specific miRNA, like miR-124, could promote the productivity of neurogenic cells (NSE-positive cells) by increasing PTBP2 expression of stem cells. Moreover, neurogenic cells derived from miR-12overexpressed stem cells successfully participate in neural restoration after SCI $[58,59]$. These findings provide important regulatory roles of miRNAs in response to CNS damage and encourage novel therapy targeting miRNAs and their target genes for SCI in the future.

\section{Function of MSC Transplantation after SCI}

3.1. Animal Model. MSC implantation exerts a therapeutic effect on experimental SCI animal models, which is supported by evidence of functional recovery [12]. However, the precise function of MSC transplantation has not been clarified until now. It is expected that after cell transplantation, MSCs would be able to differentiate into specialized neuronal and glial cell lineages. The neural differentiation ratio is low and these kinds of neurons did not show specific neuronal electrophysiological properties sometimes. Although there are controversies, the present data support that the efficacy of MSCs is mainly based on paracrine and neuroprotection functions like secreting numerous growth factors and trophic factors rather than differentiation $[42,60-62]$.

In general, the function of MSC transplantation includes both structural and functional benefits. Recent data show that MSC transplantation prevented cavity formation due to SCI and resulted in subsequent motor recovery after SCI [63-65]. At the same time, MSC admission promotes recovery of bladder and hindlimb function after SCI in rats [66]. Matsushita et al. suggest that intravenously delivered MSCs have important effects on reducing blood spinal cord barrier leakage, which could contribute to their therapeutic efficacy too [67]. MSCs are immune-privileged cells that may cross human leukocyte antigen barriers to facilitate transplantation $[41,64,68,69]$. In other studies, reduction of inflammatory infiltrates and decrease of cell apoptosis at the lesion epicenter of the spinal cord are observed after MSC transplantation [61, 70-73]. MSCs are able to reprogram macrophages from a proinflammatory M1 phenotype toward an antiinflammatory M2 phenotype and also able to regulate immune response in the injured spinal cord to provide a permissive environment for axonal extension and functional recovery [74]. Proteomic analysis of the conditioned medium of MSCs reveals a novel set of inducers for anti-inflammatory M2-like macrophages, such as monocyte chemoattractant protein-1 (MCP-1) [75]. Depletion of MCP-1 from conditional medium decreases MSCs' abilities to induce M2 macrophages and recovery from SCI. Hence, the therapeutic effect of MSC transplantation is partly based on MSCs' paracrine function, such as their ability to secrete trophic factors. Besides MCP-1, nerve growth factor (NGF), brain-derived neurotrophic factor (BDNF), neurotrophin-3 (NT-3), and many other growth factors are also increased after MSC transplantation for SCI $[42,76]$.

Generally, most stem cell therapy studies have focused on the acute or subacute phase, while there are a limited number of studies evaluating treatment efficacy during the chronic phase of SCI. There are data indicating enhanced therapeutic effects of MSC transplantation at 9 days postinjury period rather than the transplantation immediately after injury. Indeed, subacute intraparenchymal grafting of syngeneic MSCs has only a minor effect on functional recovery [77]. The function of stem cell transplantation approach for SCI might be different depending on the different time phases [16]. For chronic SCI, MSCs were transplanted 8-10 weeks after the induction of SCI and an improved functional recovery and neural regeneration was verified $[78,79]$. The systemic infusion of MSCs resulted in functional improvement, which is associated with structural changes, including stabilization of the blood-spinal cord barrier (BSCB), axonal sprouting/regeneration, and remyelination. However, anti-inflammation strategies would be needed to further improve the chronically injured spinal cord, which could be a challengeable mission of MSC transplantation for chronic SCI treatment. 
3.2. Clinical Trials. Based on preclinical experiments in SCI animal model showing MSC transplantation in the improvement of functional recovery after SCI, a series of clinical trials were performed. These experiments showed that the grafting of such cells is safe and brings benefits for some patients by using different cell application methods and transplantation procedures [80]. Collectively, autologous MSC transplantation has been shown to be an overall safe and well-tolerated procedure. Intralesional transplantation of autologous MSCs in subjects with complete SCI is safe, is feasible, and may play some roles to promote neurological improvements $[81,82]$. Consistently, an approach to personalized cell therapy in chronic SCI indicated that all patients experienced improvement, primarily in sensitivity and sphincter control, while intralesional motor activity, according to clinical and neurophysiological studies, obtained an improvement by more than $50 \%$ of the total 12 patients [83]. A case report indicated that MSC transplantation can partially promote recovery of deep sensory pathways as demonstrated by somatosensory evoked potential (SSEP) recording and alleviate neuropathic pain of a patient with traumatic complete cervical SCI [84].

However, this is not always the case. Recently, a study reported a clinical trial which made an attempt to track bone marrow-derived MSCs in a patient with a chronic cervical SCI. The results suggested that tagged bone marrowderived stem cells were detected at the patient's cervical spinal cord with magnetic resonance imaging at 48 hours, which faded after two weeks, and then disappeared after one month. Unfortunately, no clinical improvement of the neurological function had occurred at the end of this study [85]. Similarly, there are also data indicating that there is no significant improvement in Basso, Beattie, and Bresnahan (BBB) score after MSC transplantation for SCI $[86,87]$. Pal et al. reported that there is no effectiveness of the treatment involved after MSC injection for a of total 20 SCI patients during 1-3 years follow-up [88]. So, there is a common concern regarding the efficiency and reproducibility of the therapeutic use of MSCs for SCI patients. It is necessary to ensure the efficacy of MSCs as therapeutic agents for SCI before recommending clinical application of this treatment at this time.

Among various strategies for SCI treatment, it is generally accepted that stem cell transplantation is a good candidate approach leading to recovery of neural function $[89,90]$. MSC transplantation shows some improvements in a varying degree of functional recovery after SCI. However, there are many concerns before MSC application into SCI patients extensively [1]. Until now, many neuroprotection roles of MSC transplantation were reported for SCI treatment. Here comes the question: which one or none of them plays a central role? The answer to this question is important for us to understand the repair mechanisms of stem cells, consequently ensuring the effectiveness of cell therapy and developing new strategies for SCI treatment. In general, MSCs from the bone marrow or other sources are mixed with different cell populations, which display complex antigen expression profiles. Thus, we have no idea about which specific cell population produces the best therapy effects. Moreover, MSC therapy only partly improves neurological function, which is not good enough when being applied to treat chronic SCI. Hence, MSC transplantation is not an effective and reliable therapy for SCI so far. More studies need to be done before massive clinical therapy is applied.

\section{MSC and Tissue Engineering}

Considering the complex environment and cell interactions within the spinal cord, a combination of stem cells with other treatment strategies, like application of biomaterials, might bring up better results $[16,91,92]$. Generally speaking, suitable biomaterials should have some special characteristics, such as biocompatibility, porosity and permeability for the diffusion of ions, nutrients, and waste products, and biodegradability. More importantly, biomaterials should have the capacity of mimicking the extracellular matrix (ECM) of CNS tissues, which provides a more permissive environment for cell survival, growth, migration, and differentiation [93]. Therefore, they are expected to provide an adequate environment for the regeneration of the injured tissues. Taking into account the well-known capacity of MSCs to secrete paracrine factors and the neural protection function when transplanted into spinal cord lesion models, their combination with a 3D matrix holds great promise to SCI repair [94-97].

Silks are naturally occurring polymers that have been used clinically as sutures for centuries. Silk fibroin in various formats has been shown to support cell adhesion, proliferation, and differentiation in vitro with a variety of cells and promote tissue repair in vivo. The work from our groups found that electrospun silk fibroin (SF) nanofibers support the adhesion and growth of neural cells. Interestingly, our data indicated that nanofibers could help neurons form the three-dimensional network by providing the supported substrate. At the same time, SF nanofibers promote neurite outgrowth and astrocyte migration [98]. Furthermore, we proposed that the diameter of biodegradable SF polymer could influence the growth behavior of cells in vitro. In conclusion, our in vitro data demonstrate that smaller diameter and aligned electrospun tussah silk fibroin represent valuable scaffolds for supporting and promoting growth and migration of stem cells, thus raising the possibility of manipulating SF scaffolds to enhance growth, homing, and therapeutic potential of stem cells in cellular therapy [99].

Besides natural biomaterials, biodegradable synthetic scaffolds have been used to support and improve the stem cell regenerative performance too. Hydrogels are particularly appealing for neural tissue repair because of their special physical properties such as being injected into the body in a localized and noninvasive manner $[100,101]$. In a more recent study, a new agarose/carbomer-based hydrogel which combines different strategies to optimize MSC viability was evaluated. The study demonstrates that a combination of MSCs and biomimetic hydrogel is able to immunomodulate the proinflammatory environment in a SCI mouse model and promote a favorable regeneration environment in situ significantly [96]. This study presents the ability of a 3D ECM deposition to increase adherence and viability of loaded human MSCs. 


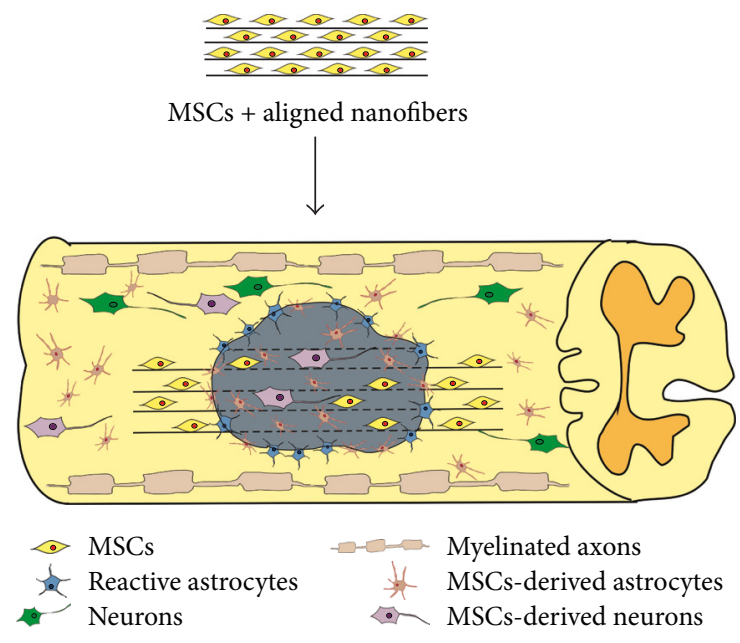

FIGURE 1: Biomaterials with different topographies have the capacity of mimicking the ECM of the CNS tissue and further influencing the growth behavior of transplanted stem cells. The aligned nanofibers were supposed to improve the migration and differentiation of cells after SCI.

As mentioned previously, the biological behavior of MSCs in vivo is closely related to their regeneration ability. For instance, the migratory and differentiation capacities of MSCs are closely related to their engraftment and regeneration ability. Therefore, one of the principal functions of nerve tissue-engineered scaffolds is to direct neural cell behavior such as growth, cell spreading, migration, and differentiation and to respond to the environment in a targeted implantable tissue. Hyatt et al. showed that MSCs delivered via scaffold formed longitudinally aligned layers growing over the spinal cord lesion site [102]. Host neurites within the spinal cord tissue were found to migrate into the graft. In addition, the layered architecture of the scaffold appeared to induce cell/ tissue polarity and promote longitudinal growth of neurites within the graft [103]. Also, multichannel/laminin (LN) silk scaffolds could mediate cell migration, stimulate blood capillary formation, and promote axonal extension, suggesting a strong correlation between scaffold topography and growth behavior of stem cells [104]. More intensive studies are required for the investigation of the activities of stem cells after being combined with biomaterials to offer insights into the design and development of nerve tissue engineering scaffold especially for SCI (Figure 1) [105].

\section{MSC-Derived Exosomes as a Promising Therapeutic Vesicle for SCI}

Secretomes, also called extracellular vesicles, are several groups of secreted vesicles, which could be classified as exosomes, microvesicles (MVs), and apoptotic bodies. Exosomes $(30-100 \mathrm{~nm})$ can be distinguished from MVs $(100-1000 \mathrm{~nm})$ and apoptotic bodies (1000-5000 $\mathrm{nm}$ ) according to their size, morphology, origin, composition, and density [106]. They are membrane-bound vesicles which are secreted naturally by many types of cells. Exosomes contain proteins, lipids, and various nucleic acids, including mRNAs, miRNAs, and long noncoding RNAs (lncRNAs) [107]. These exosomal
RNAs can be taken up by distant cells and lead to the protein translation in the target cells. Thus, exosomes function as natural carriers of signal molecules and further act as physiological regulators of cell-to-cell communication. Recently, several studies indicate that lncRNAs in cancer exosomes can act as diagnostic and prognostic biomarkers [108, 109]. The discovery of their regulatory roles on distinct physiological or pathological conditions has brought increasing attention to exosomes.

MSC exosomes, like exosomes in general, carry exosomeassociated markers such as Alix, tetraspanins (CD9, CD63, and CD81), and heat-shock proteins including Hsp60, Hsp70, and Hsp90. Besides, the other distinct composition of MSC exosomes depends on cell sources (which tissue MSCs were isolated from) and their physiological states [93]. There are around 857 unique gene products and more than 150 kinds of miRNAs expressed in MSC exosomes, suggesting that exosomal proteins and RNAs could form different functional RNA-protein complexes to perform diverse cellular responses [110].

Exosomes derived from MSCs may have a comparable therapeutic potential as cells themselves. Studies showed that exosomes derived from MSCs have therapeutic potential for many kinds of diseases [111]. For example, exosomes derived from MSCs exert protective effects on myocardial ischemia/reperfusion injury. MSC-derived exosomes can reverse the degeneration of neurons and astrocytes, as well as synaptic loss in hippocampus of diabetic mice [112]. Zhang et al. demonstrated that exosomes derived from MSCs can promote axonal growth of cortical neurons, indicating a potential therapeutic strategy to enhance axonal growth after CNS injury [113]. Moreover, MSC exosomes contribute to the improvement of impaired neurological functions, implying their potential clinical applications [114]. These results raise a possibility that exosomes derived from MSCs might be a promising therapeutic tool for SCI. However, there still lack direct experimental evidence that administration of cell-free exosomes generated from MSCs promotes axonal growth and improves neurological functions after SCI.

In general, MSCs represent the most promising source of exosomes for the neurotherapeutic applications. MSCs were found to produce large amounts of exosomes and could be used as the source to produce commercially sustainable production of exosomes. Exosomes are less immunogenic, more biocompatible and stable, compared to other existing viral or liposome-based gene delivery. It has been proposed that exosomes may cross the blood-brain barrier and enter into the CNS via intercellular junctions of endothelial cells. In addition, exosomes can be modified with genetic engineering, which will improve their therapeutic efficiency. These characteristics suggest that exosomes can be developed as an ideal vehicle for therapeutic delivery. However, exosomes contain a diverse array of signaling molecules with complicated functions, which could raise multiple safety issues. Therefore, it is critical for future studies to engineer exosome delivery systems containing high density of the defined therapeutic molecules, which target specific cells on the given situations. 


\section{Molecular Mechanisms after MSC Transplantation for SCI}

It is well known that MSCs can produce various growth factors, neuroprotective cytokines and chemokines, including HGF, VEGF, fibroblast growth factor (FGF), BDNF, and NGF, which could indeed underlie functional benefits associated with MSC transplantation [115, 116]. Recent studies demonstrated that MSCs are an efficient source of HGF and suggest that the therapeutic effects of MSC transplantation are partly mediated by HGF secreted by these cells [117]. HGF blocked secretion of transforming growth factor- $\beta$ (TGF- $\beta$ ) from activated astrocytes and prevented expression of specific chondroitin sulfate proteoglycan (CSPG) species. Transplantation of HGFoverexpressing MSCs markedly decreased Neurocan expression and glycosaminoglycan chain deposition around hemisection lesions in the spinal cord. Animals treated with HGF-MSCs showed increased axonal growth and improvement in functional recovery [118], which is consistent with the view that HGF have been identified as attractive signals for guidance of motor axons to the target tissue [119]. In addition, HGF has been reported to provide therapeutic effects in central nerve injury, such as the suppression of demyelination, apoptosis, and bloodbrain barrier disruption, through the c-Met receptors that are upregulated after injury in rat neurons, oligodendrocytes, and astrocytes [120].

Besides growth factors which act as paracrine signaling, immunological cytokines are also involved in the process of stem cell therapy after SCI. For instance, transplantation of MSCs into a lesion spinal cord reduced the secretion of TNF $\alpha$, IL-4, IL-1 $\beta$, IL-2, IL-6, and IL-12 when compared to that of the saline-treated controls [121-123]. Particularly, implantation of MSCs prevents second-phase neuronal injury by suppressing lymphocyte and microglia effects and reduces the inflammatory reaction in the local environment after SCI [124]. These results indicate that neuronal survival after lesion might occur through cytokine release and immunomodulation followed by MSC administration.

Previous studies reveled that MSC implantation modulates glial scar formation after SCI. One of these reports concludes that MSC treatment after SCI upregulates matrix metalloproteinase- (MMP-) 2 levels and reduces the formation of the glial scar thereby creating an environment suitable for endogenous regeneration mechanisms [125]. In addition, it was shown that human MSCs deposit fibronectin (FN) following SCI, which is a well-known inducer of axonal growth, as well as a component of the extracellular matrix (ECM) [126]. Importantly, it has been shown that FN secreted by MSCs are essential for neurite elongation of neuronal differentiating MSCs as well as nerve fiber regeneration after SCI. Laminin is a well-known inducer of axonal growth too, as well a component of the ECM associated to neural progenitors. Laminin and TGF- $\beta$ expression have also been increased in the injured spinal cord after MSC admission for SCI. The in vivo data suggest that laminin can be the paracrine factor mediating the proregenerative effects of MSCs in spinal cord injury [127].
Apoptosis-related pathways have been found involved in SCI after MSC transplantation. Recent findings suggest that caspase-3-mediated apoptosis on both neurons and oligodendrocytes following SCI was significantly downregulated by MSCs, which was regulated through stimulation of endogenous survival signaling pathways, PI3K/Akt, and the MAPK/ERK1/2-cascade [128]. Extracellular-adjusting protein kinases 1 and $2(\mathrm{ERK} 1 / 2)$ are important intracellular signaling molecules that are members of the MAPK family. Consistently, Wang et al. showed that transplanting MSCs activates ERK1/2 in spinal cords of ischemia-reperfusion injury rats and improves nerve function [129]. At the same time, $\mathrm{Bcl} 2$ expression increased, whereas Bax expression decreased following stem cell transplantation. There are also data indicating that transplantation of MSCs for neurological disorders inhibited apoptosis and the protein expression of c-Jun N-terminal kinase and p38 as well triggered the phosphorylation of P-42/44 ERK1/2 [130]. However, it remains undetermined whether MAPK/ERK1/2-cascade participates in other mechanisms beyond inhibition of apoptosis, such as secretion of various neurotrophic factors that promote the regeneration or improving the axon regeneration microenvironment.

It has been demonstrated that $\mathrm{Wnt} / \beta$-catenin signaling plays a key role in promoting the differentiation of MSCs toward a neuronal fate. Wnt-7a enhanced neuronal differentiation in MSCs via both canonical and noncanonical signaling pathways [131]. Contusion spinal cord injury induced a time-dependent increase in Wnt expression from 6 hours until 28 days postinjury. Specially, after an initial decrease by 1 day, an increase in phosphorylation of the Wnt coreceptor, low-density lipoprotein receptor-related protein 6 (LRP6), and an increase in active $\beta$-catenin protein were shown, indicating that canonical Wnt signaling is active in the adult spinal cord and in cells around the wound epicenter after SCI [132]. There is some evidence that spinal radial glia, neural progenitors in zebrafish, exhibit canonical Wnt/ $\beta$ catenin activity as they undergo neurogenesis following spinal cord transection [133]. Wnt/ $\beta$-catenin signaling may promote axon regrowth either directly or through induction of secondary pathways in radial glia, suggesting important regulating roles in neural regeneration. In addition, overexpression of Dkk1b, an inhibitor of $\mathrm{Wnt} / \beta$-catenin signaling, hampers locomotor recovery, axon regeneration, and glial bridge formation in the regenerating spinal cord of adult zebrafish. However, it is still undetermined in mammals that whether $\mathrm{Wnt} / \beta$-catenin signaling is the activated response to SCI after MSC implantation, which might be explored in the near future (Figure 2).

\section{Conclusions}

MSCs are considered as the most promising sources for cellular therapies following SCI. The mechanisms underlying the biological behavior of MSCs and their complicated function in vivo are not fully understood, which is very important for improving the therapeutic effects and for designing better therapeutic strategies. A combination of MSCs with nerve tissue-engineered scaffolds can direct cell behavior such as 


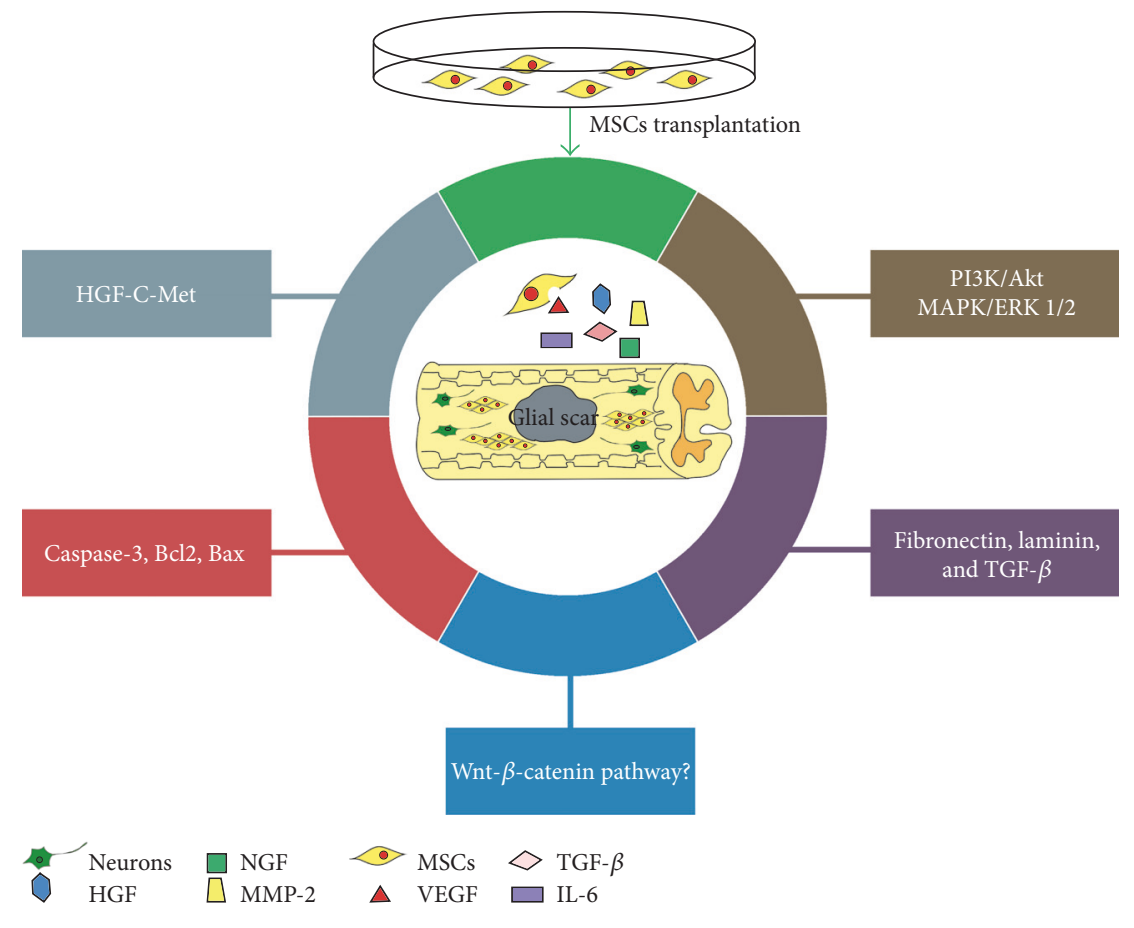

FIGURE 2: Regulatory molecular mechanisms involved in SCI after MSC transplantation.

growth, cell spreading, migration, and differentiation and respond to the local environment after SCI. More intensive studies are required for the investigation of the activities of cells after combined with biomaterials to offer insights into the design and development of nerve tissue-engineering scaffold for SCI. MSCs represent the most promising source of exosomes for the neurotherapeutic applications, and exosomes derived from MSCs may have a comparable therapeutic potential as cells themselves. Notably, MSCs respond to the local environment in multiple ways. MSCs produce various growth factors, neuroprotective cytokines and chemokines, reduce the inflammatory reaction by suppressing lymphocyte effects, modulate glial scar formation, downregulate Caspase-3 mediated apoptosis by activating ERK1/2cascade, and so forth. In addition, Wnt/ $\beta$-catenin signaling pathway might also play important regulatory roles for MSC behavior after SCI. In conclusion, it is of considerable interest to investigate the biological behavior and function of MSCs, especially after SCI treatment. The regulatory mechanisms directing MSC behavior in molecular details will undoubtedly provide valuable insights in improving the MSC-mediated therapy effects and designing better therapeutic strategies.

\section{Conflicts of Interest}

All authors have none to declare.

\section{Authors' Contributions}

Huanxiang Zhang designed study and made the decision to submit the paper for publication, and Jing $\mathrm{Qu}$ wrote the paper.

\section{Acknowledgments}

This work was supported by the Natural Science Foundation of Jiangsu Province (Grant no. BK20141198).

\section{References}

[1] A. Goel, "Stem cell therapy in spinal cord injury: hollow promise or promising science?" Journal of Craniovertebral Junction \& Spine, vol. 7, no. 2, pp. 121-126, 2016.

[2] J. W. Tan, K. Y. Wang, G. J. Liao, F. M. Chen, and M. Z. Mu, "Neuroprotective effect of methylprednisolone combined with placenta-derived mesenchymal stem cell in rabbit model of spinal cord injury," International Journal of Clinical and Experimental Pathology, vol. 8, no. 8, pp. 8976-8982, 2015.

[3] K. Zweckberger, C. S. Ahuja, Y. Liu, J. Wang, and M. G. Fehlings, "Self-assembling peptides optimize the post-traumatic milieu and synergistically enhance the effects of neural stem cell therapy after cervical spinal cord injury," Acta Biomaterialia, vol. 42, pp. 77-89, 2016.

[4] S. Q. Zhang, M. F. Wu, J. B. Liu, Y. Li, Q. S. Zhu, and R. Gu, "Transplantation of human telomerase reverse transcriptase gene-transfected Schwann cells for repairing spinal cord injury," Neural Regeneration Research, vol. 10, no. 12, pp. 2040-2047, 2015.

[5] Y. Zhao, Y. Zuo, X. L. Wang et al., "Effect of neural stem cell transplantation combined with erythropoietin injection on axon regeneration in adult rats with transected spinal cord injury," Genetics and Molecular Research (GMR), vol. 14, no. 4, pp. 17799-17808, 2015.

[6] S. Tashiro, S. Nishimura, H. Iwai et al., "Functional recovery from neural stem/progenitor cell transplantation combined with treadmill training in mice with chronic spinal cord injury," Scientific Reports, vol. 6, no. 1, p. 30898, 2016. 
[7] S. Kawabata, M. Takano, Y. Numasawa-Kuroiwa et al., "Grafted human iPS cell-derived oligodendrocyte precursor cells contribute to robust remyelination of demyelinated axons after spinal cord injury," Stem Cell Reports, vol. 6, no. 1 , pp. 1-8, 2016.

[8] W. Marcol, W. Slusarczyk, A. L. Sieron, H. KoryciakKomarska, and J. Lewin-Kowalik, "Bone marrow stem cells delivered into the subarachnoid space via cisterna magna improve repair of injured rat spinal cord white matter," International Journal of Clinical and Experimental Medicine, vol. 8, no. 9, pp. 14680-14692, 2015.

[9] S. Wu, G. Cui, H. Shao, Z. Du, J. C. Ng, and C. Peng, “The cotransplantation of olfactory ensheathing cells with bone marrow mesenchymal stem cells exerts antiapoptotic effects in adult rats after spinal cord injury," Stem Cells International, vol. 2015, Article ID 516215, 13 pages, 2015.

[10] M. M. Mortazavi, O. A. Harmon, N. Adeeb, A. Deep, and R. S. Tubbs, "Treatment of spinal cord injury: a review of engineering using neural and mesenchymal stem cells," Clinical Anatomy, vol. 28, no. 1, pp. 37-44, 2015.

[11] Y. Huang, Y. Zheng, C. Jin, X. Li, L. Jia, and W. Li, "Long non-coding RNA H19 inhibits adipocyte differentiation of bone marrow mesenchymal stem cells through epigenetic modulation of histone deacetylases," Scientific Reports, vol. 6, no. 1, p. 28897, 2016.

[12] F. R. Melo, R. B. Bressan, S. Forner et al., "Transplantation of human skin-derived mesenchymal stromal cells improves locomotor recovery after spinal cord injury in rats," Cellular and Molecular Neurobiology, pp. 1-7, 2016.

[13] H. M. Gransee, W. Z. Zhan, G. C. Sieck, and C. B. Mantilla, "Localized delivery of brain-derived neurotrophic factorexpressing mesenchymal stem cells enhances functional recovery following cervical spinal cord injury," Journal of Neurotrauma, vol. 32, no. 3, pp. 185-193, 2015.

[14] N. Derakhshanrad, H. Saberi, K. Tayebi Meybodi et al., "Case report: combination therapy with mesenchymal stem cells and granulocyte-colony stimulating factor in a case of spinal cord injury," Basic and Clinical Neuroscience, vol. 6, no. 4, pp. 299-305, 2015.

[15] L. A. Marquez-Curtis and A. Janowska-Wieczorek, "Enhancing the migration ability of mesenchymal stromal cells by targeting the SDF-1/CXCR4 axis," BioMed Research International, vol. 2013, Article ID 561098, 15 pages, 2013.

[16] S. V. White, C. E. Czisch, M. H. Han, C. D. Plant, A. R. Harvey, and G. W. Plant, "Intravenous transplantation of mesenchymal progenitors distribute solely to the lungs and improve outcomes in cervical spinal cord injury," Stem Cells, vol. 34, no. 7, pp. 1812-1825, 2016.

[17] D. Cizkova, J. Rosocha, I. Vanicky, S. Jergova, and M. Cizek, "Transplants of human mesenchymal stem cells improve functional recovery after spinal cord injury in the rat," Cellular and Molecular Neurobiology, vol. 26, no. 7-8, pp. 11671180, 2006.

[18] M. Osaka, O. Honmou, T. Murakami et al., "Intravenous administration of mesenchymal stem cells derived from bone marrow after contusive spinal cord injury improves functional outcome," Brain Research, vol. 1343, pp. 226-235, 2010.

[19] T. Amemori, P. Jendelova, K. Ruzickova, D. Arboleda, and E. Sykova, "Co-transplantation of olfactory ensheathing glia and mesenchymal stromal cells does not have synergistic effects after spinal cord injury in the rat," Cytotherapy, vol. 12, no. 2, pp. 212-225, 2010.

[20] A. S. Cornelissen, M. W. Maijenburg, M. A. Nolte, and C. Voermans, "Organ-specific migration of mesenchymal stromal cells: who, when, where and why?" Immunology Letters, vol. 168, no. 2, pp. 159-169, 2015.

[21] J. Li, W. Guo, M. Xiong et al., "Effect of SDF-1/CXCR4 axis on the migration of transplanted bone mesenchymal stem cells mobilized by erythropoietin toward lesion sites following spinal cord injury," International Journal of Molecular Medicine, vol. 36, no. 5, pp. 1205-1214, 2015.

[22] Z. Zhilai, M. Biling, Q. Sujun et al., "Preconditioning in lowered oxygen enhances the therapeutic potential of human umbilical mesenchymal stem cells in a rat model of spinal cord injury," Brain Research, vol. 1642, pp. 426-435, 2016.

[23] A. Badner, R. Vawda, A. Laliberte et al., "Early intravenous delivery of human brain stromal cells modulates systemic inflammation and leads to vasoprotection in traumatic spinal cord injury," Stem Cells Translational Medicine, vol. 5, no. 8, pp. 991-1003, 2016.

[24] S. Takashima, M. Mkrtchyan, A. Younossi-Hartenstein, J. R. Merriam, and V. Hartenstein, "The behaviour of Drosophila adult hindgut stem cells is controlled by Wnt and Hh signalling," Nature, vol. 454, no. 7204, pp. 651-655, 2008.

[25] S. Takashima and V. Hartenstein, "Genetic control of intestinal stem cell specification and development: a comparative view," Stem Cell Reviews, vol. 8, no. 2, pp. 597-608, 2012.

[26] P. Dmitriev, E. Kiseleva, O. Kharchenko et al., "Dux4 controls migration of mesenchymal stem cells through the Cxcr4-Sdf1 axis," Oncotarget, vol. 7, no. 40, pp. 65090-65108, 2016.

[27] L. Zachar, D. Bacenkova, and J. Rosocha, "Activation, homing, and role of the mesenchymal stem cells in the inflammatory environment," Journal of Inflammation Research, vol. 9, pp. 231-240, 2016.

[28] Q. Xu, J. Wang, J. He et al., "Impaired CXCR4 expression and cell engraftment of bone marrow-derived cells from aged atherogenic mice," Atherosclerosis, vol. 219, no. 1, pp. 92-99, 2011.

[29] L. A. Marquez-Curtis, H. Gul-Uludag, P. Xu, J. Chen, and A. Janowska-Wieczorek, "CXCR4 transfection of cord blood mesenchymal stromal cells with the use of cationic liposome enhances their migration toward stromal cell-derived factor1," Cytotherapy, vol. 15, no. 7, pp. 840-849, 2013.

[30] G. D. Wang, Y. X. Liu, X. Wang, Y. L. Zhang, Y. D. Zhang, and F. Xue, "The SDF-1/CXCR4 axis promotes recovery after spinal cord injury by mediating bone marrow-derived from mesenchymal stem cells," Oncotarget, vol. 8, no. 7, pp. 11629-11640, 2017.

[31] H. S. Hong, J. Lee, E. Lee et al., "A new role of substance P as an injury-inducible messenger for mobilization of CD29(+) stromal-like cells," Nature Medicine, vol. 15, no. 4, pp. 425435, 2009.

[32] I. Petit, M. Szyper-Kravitz, A. Nagler et al., "G-CSF induces stem cell mobilization by decreasing bone marrow SDF-1 and up-regulating CXCR4," Nature Immunology, vol. 3, no. 7, pp. 687-694, 2002.

[33] B. Zheng, C. Wang, L. He et al., "Neural differentiation of mesenchymal stem cells influences chemotactic responses to HGF," Journal of Cellular Physiology, vol. 228, no. 1, pp. 149-162, 2013. 
[34] A. Jaerve, J. Schira, and H. W. Muller, "Concise review: the potential of stromal cell-derived factor 1 and its receptors to promote stem cell functions in spinal cord repair," Stem Cells Translational Medicine, vol. 1, no. 10, pp. 732-739, 2012.

[35] L. J. Wang, R. P. Zhang, and J. D. Li, "Transplantation of neurotrophin-3-expressing bone mesenchymal stem cells improves recovery in a rat model of spinal cord injury," Acta Neurochirurgica, vol. 156, no. 7, pp. 1409-1418, 2014.

[36] X. C. Qiu, H. Jin, R. Y. Zhang et al., "Donor mesenchymal stem cell-derived neural-like cells transdifferentiate into myelin-forming cells and promote axon regeneration in rat spinal cord transection," Stem Cell Research \& Therapy, vol. 6, no. 1, p. 105, 2015.

[37] A. M. Parr, I. Kulbatski, X. H. Wang, A. Keating, and C. H. Tator, "Fate of transplanted adult neural stem/progenitor cells and bone marrow-derived mesenchymal stromal cells in the injured adult rat spinal cord and impact on functional recovery," Surgical Neurology, vol. 70, no. 6, pp. 600-607, 2008.

[38] K. Zhang, Z. Liu, G. Li et al., "Electro-acupuncture promotes the survival and differentiation of transplanted bone marrow mesenchymal stem cells pre-induced with neurotrophin-3 and retinoic acid in gelatin sponge scaffold after rat spinal cord transection," Stem Cell Reviews, vol. 10, no. 4, pp. 612$625,2014$.

[39] C. Wang, D. Shi, X. Song, Y. Chen, L. Wang, and X. Zhang, "Calpain inhibitor attenuates ER stress-induced apoptosis in injured spinal cord after bone mesenchymal stem cells transplantation," Neurochemistry International, vol. 97, pp. 15-25, 2016.

[40] D. Arboleda, S. Forostyak, P. Jendelova et al., "Transplantation of predifferentiated adipose-derived stromal cells for the treatment of spinal cord injury," Cellular and Molecular Neurobiology, vol. 31, no. 7, pp. 1113-1122, 2011.

[41] Y. Kim, S. H. Jo, W. H. Kim, and O. K. Kweon, "Antioxidant and anti-inflammatory effects of intravenously injected adipose derived mesenchymal stem cells in dogs with acute spinal cord injury," Stem Cell Research \& Therapy, vol. 6, no. 1, p. 229, 2015.

[42] H. J. Chung, W. H. Chung, J. H. Lee et al., "Expression of neurotrophic factors in injured spinal cord after transplantation of human-umbilical cord blood stem cells in rats," Journal of Veterinary Science, vol. 17, no. 1, pp. 97-102, 2016.

[43] C. H. Yeng, P. J. Chen, H. K. Chang et al., "Attenuating spinal cord injury by conditioned medium from human umbilical cord blood-derived CD34(+) cells in rats," Taiwanese Journal of Obstetrics \& Gynecology, vol. 55, no. 1, pp. 85-93, 2016.

[44] R. P. Ahmed, K. H. Haider, J. Shujia, M. R. Afzal, and M. Ashraf, "Sonic Hedgehog gene delivery to the rodent heart promotes angiogenesis via iNOS/netrin-1/PKC pathway," PloS One, vol. 5, no. 1, article e8576, 2010.

[45] G. Kumagai, P. Tsoulfas, S. Toh, I. McNiece, H. M. Bramlett, and W. D. Dietrich, "Genetically modified mesenchymal stem cells (MSCs) promote axonal regeneration and prevent hypersensitivity after spinal cord injury," Experimental Neurology, vol. 248, pp. 369-380, 2013.

[46] R. P. Zhang, L. J. Wang, S. He, J. Xie, and J. D. Li, "Effects of magnetically guided, SPIO-labeled, and neurotrophin-3 gene-modified bone mesenchymal stem cells in a rat model of spinal cord injury," Stem Cells International, vol. 2016, Article ID 2018474, 2016.
[47] Y. M. Park, S. H. Han, S. K. Seo, K. A. Park, W. T. Lee, and J. E. Lee, "Restorative benefits of transplanting human mesenchymal stromal cells overexpressing arginine decarboxylase genes after spinal cord injury," Cytotherapy, vol. 17, no. 1, pp. 25-37, 2015.

[48] X. Y. Lin, B. Q. Lai, X. Zeng et al., "Cell transplantation and neuroengineering approach for spinal cord injury treatment: a summary of current laboratory findings and review of literature," Cell Transplantation, vol. 25, no. 8, pp. 1425-1438, 2016.

[49] L. L. Xiong, Y. Li, F. F. Shang et al., "Chondroitinase administration and pcDNA3.1-BDNF-BMSC transplantation promote motor functional recovery associated with NGF expression in spinal cord-transected rat," Spinal Cord, vol. 54, no. 12, pp. 1088-1095, 2016.

[50] H. A. Abbaszadeh, T. Tiraihi, A. Noori-Zadeh, A. R. Delshad, M. Sadeghizade, and T. Taheri, "Human ciliary neurotrophic factor-overexpressing stable bone marrow stromal cells in the treatment of a rat model of traumatic spinal cord injury," Cytotherapy, vol. 17, no. 7, pp. 912-921, 2015.

[51] X. Zeng, X. C. Qiu, Y. H. Ma et al., "Integration of donor mesenchymal stem cell-derived neuron-like cells into host neural network after rat spinal cord transection," Biomaterials, vol. 53, pp. 184-201, 2015.

[52] Y. Gong, H. Wang, and H. Xia, "Stable transfection into rat bone marrow mesenchymal stem cells by lentivirusmediated NT-3," Molecular Medicine Reports, vol. 11, no. 1, pp. 367-373, 2015.

[53] A. Karthikeyan, R. Patnala, S. P. Jadhav, E. A. Ling, and S. T. Dheen, "MicroRNAs: key players in microglia and astrocyte mediated inflammation in CNS pathologies," Current Medicinal Chemistry, vol. 23, no. 30, pp. 3528-3546, 2016.

[54] T. Hwang, C. K. Park, A. K. Leung et al., "Dynamic regulation of RNA editing in human brain development and disease," Nature Neuroscience, vol. 19, no. 8, pp. 1093-1099, 2016.

[55] F. He, Y. Ren, E. Shi, K. Liu, L. Yan, and X. Jiang, "Overexpression of microRNA-21 protects spinal cords against transient ischemia," The Journal of Thoracic and Cardiovascular Surgery, vol. 152, no. 6, pp. 1602-1608, 2016.

[56] T. Theis, M. Yoo, C. S. Park et al., "Lentiviral delivery of miR$133 \mathrm{~b}$ improves functional recovery after spinal cord injury in mice," Molecular Neurobiology, pp. 1-13, 2016.

[57] D. D. Licatalosi, M. Yano, J. J. Fak et al., "Ptbp2 represses adult-specific splicing to regulate the generation of neuronal precursors in the embryonic brain," Genes \& Development, vol. 26, no. 14, pp. 1626-1642, 2012.

[58] Y. Zhao, H. Jiang, X. W. Liu, L. B. Xiang, D. P. Zhou, and J. T. Chen, "MiR-124 promotes bone marrow mesenchymal stem cells differentiation into neurogenic cells for accelerating recovery in the spinal cord injury," Tissue \& Cell, vol. 47, no. 2, pp. 140-146, 2015.

[59] W. Xu, P. Li, K. Qin, X. Wang, and X. Jiang, "miR-124 regulates neural stem cells in the treatment of spinal cord injury," Neuroscience Letters, vol. 529, no. 1, pp. 12-17, 2012.

[60] A. B. Spejo, J. L. Carvalho, A. M. Goes, and A. L. Oliveira, "Neuroprotective effects of mesenchymal stem cells on spinal motoneurons following ventral root axotomy: synapse stability and axonal regeneration," Neuroscience, vol. 250, pp. 715732,2013

[61] C. Gu, H. Li, C. Wang et al., "Bone marrow mesenchymal stem cells decrease CHOP expression and neuronal apoptosis 
after spinal cord injury," Neuroscience Letters, vol. 636, pp. 282-289, 2017.

[62] G. D. Schroeder, C. K. Kepler, and A. R. Vaccaro, "The use of cell transplantation in spinal cord injuries," The Journal of the American Academy of Orthopaedic Surgeons, vol. 24, no. 4, pp. 266-275, 2016.

[63] M. Yousefifard, F. Nasirinezhad, H. Shardi Manaheji, A. Janzadeh, M. Hosseini, and M. Keshavarz, "Human bone marrow-derived and umbilical cord-derived mesenchymal stem cells for alleviating neuropathic pain in a spinal cord injury model," Stem Cell Research \& Therapy, vol. 7, no. 1, p. 36, 2016.

[64] M. Boido, D. Garbossa, M. Fontanella, A. Ducati, and A. Vercelli, "Mesenchymal stem cell transplantation reduces glial cyst and improves functional outcome after spinal cord compression," World Neurosurgery, vol. 81, no. 1, pp. 183-190, 2014.

[65] S. Watanabe, K. Uchida, H. Nakajima et al., "Early transplantation of mesenchymal stem cells after spinal cord injury relieves pain hypersensitivity through suppression of painrelated signaling cascades and reduced inflammatory cell recruitment," Stem Cells, vol. 33, no. 6, pp. 1902-1914, 2015.

[66] W. B. Park, S. Y. Kim, S. H. Lee, H. W. Kim, J. S. Park, and J. K. Hyun, "The effect of mesenchymal stem cell transplantation on the recovery of bladder and hindlimb function after spinal cord contusion in rats," BMC Neuroscience, vol. 11, no. 1, p. 119, 2010.

[67] T. Matsushita, K. L. Lankford, E. J. Arroyo et al., "Diffuse and persistent blood-spinal cord barrier disruption after contusive spinal cord injury rapidly recovers following intravenous infusion of bone marrow mesenchymal stem cells," Experimental Neurology, vol. 267, pp. 152-164, 2015.

[68] V. Zhukareva, M. Obrocka, J. D. Houle, I. Fischer, and B. Neuhuber, "Secretion profile of human bone marrow stromal cells: donor variability and response to inflammatory stimuli," Cytokine, vol. 50, no. 3, pp. 317-321, 2010.

[69] K. T. Wright, W. El Masri, A. Osman, J. Chowdhury, and W. E. Johnson, "Concise review: bone marrow for the treatment of spinal cord injury: mechanisms and clinical applications," Stem Cells, vol. 29, no. 2, pp. 169-178, 2011.

[70] T. Tsumuraya, H. Ohtaki, D. Song et al., "Human mesenchy$\mathrm{mal}$ stem/stromal cells suppress spinal inflammation in mice with contribution of pituitary adenylate cyclase-activating polypeptide (PACAP)," Journal of Neuroinflammation, vol. 12, no. 1, p. 35, 2015.

[71] M. B. Abrams, C. Dominguez, K. Pernold et al., "Multipotent mesenchymal stromal cells attenuate chronic inflammation and injury-induced sensitivity to mechanical stimuli in experimental spinal cord injury," Restorative Neurology and Neuroscience, vol. 27, no. 4, pp. 307-321, 2009.

[72] W. Gu, F. Zhang, Q. Xue, Z. Ma, P. Lu, and B. Yu, “Transplantation of bone marrow mesenchymal stem cells reduces lesion volume and induces axonal regrowth of injured spinal cord," Neuropathology : Official Journal of the Japanese Society of Neuropathology, vol. 30, no. 3, pp. 205-217, 2010.

[73] X. Zeng, Y. S. Zeng, Y. H. Ma et al., "Bone marrow mesenchymal stem cells in a three-dimensional gelatin sponge scaffold attenuate inflammation, promote angiogenesis, and reduce cavity formation in experimental spinal cord injury," Cell Transplantation, vol. 20, no. 11-12, pp. 1881-1899, 2011.

[74] H. Nakajima, K. Uchida, A. R. Guerrero et al., "Transplantation of mesenchymal stem cells promotes an alternative pathway of macrophage activation and functional recovery after spinal cord injury," Journal of Neurotrauma, vol. 29, no. 8, pp. 1614-1625, 2012.

[75] G. Zheng, M. Ge, G. Qiu, Q. Shu, and J. Xu, "Mesenchymal stromal cells affect disease outcomes via macrophage polarization," Stem Cells International, vol. 2015, Article ID 989473, 11 pages, 2015.

[76] L. Tang, X. Lu, R. Zhu et al., "Adipose-derived stem cells expressing the neurogenin-2 promote functional recovery after spinal cord injury in rat," Cellular and Molecular Neurobiology, vol. 36, no. 5, pp. 657-667, 2016.

[77] B. Sandner, M. Ciatipis, M. Motsch, I. Soljanik, N. Weidner, and A. Blesch, "Limited functional effects of subacute syngeneic bone marrow stromal cell transplantation after rat spinal cord contusion injury," Cell Transplantation, vol. 25, no. 1, pp. 125-139, 2016.

[78] T. Morita, M. Sasaki, Y. Kataoka-Sasaki et al., "Intravenous infusion of mesenchymal stem cells promotes functional recovery in a model of chronic spinal cord injury," Neuroscience, vol. 335, pp. 221-231, 2016.

[79] S. H. Lee, Y. Kim, D. Rhew et al., "Effect of the combination of mesenchymal stromal cells and chondroitinase $\mathrm{ABC}$ on chronic spinal cord injury," Cytotherapy, vol. 17, no. 10, pp. 1374-1383, 2015.

[80] X. Miao, X. Wu, and W. Shi, "Umbilical cord mesenchymal stem cells in neurological disorders: a clinical study," Indian Journal of Biochemistry \& Biophysics, vol. 52, no. 2, pp. 140-146, 2015.

[81] M. V. Mendonca, T. F. Larocca, B. S. de Freitas Souza et al., "Safety and neurological assessments after autologous transplantation of bone marrow mesenchymal stem cells in subjects with chronic spinal cord injury," Stem Cell Research \& Therapy, vol. 5, no. 6, p. 126, 2014.

[82] J. W. Hur, T. H. Cho, D. H. Park, J. B. Lee, J. Y. Park, and Y. G. Chung, "Intrathecal transplantation of autologous adipose-derived mesenchymal stem cells for treating spinal cord injury: a human trial," The Journal of Spinal Cord Medicine, vol. 39, no. 6, pp. 655-664, 2016.

[83] J. Vaquero, M. Zurita, M. A. Rico et al., “An approach to personalized cell therapy in chronic complete paraplegia: the Puerta de Hierro phase I/II clinical trial," Cytotherapy, vol. 18, no. 8, pp. 1025-1036, 2016.

[84] R. Hua, P. Li, X. Wang et al., "Evaluation of somatosensory evoked potential and pain rating index in a patient with spinal cord injury accepted cell therapy," Pain Physician, vol. 19, no. 4, pp. E659-E666, 2016.

[85] A. Chotivichit, M. Ruangchainikom, P. Chiewvit, A. Wongkajornsilp, and K. Sujirattanawimol, "Chronic spinal cord injury treated with transplanted autologous bone marrowderived mesenchymal stem cells tracked by magnetic resonance imaging: a case report," Journal of Medical Case Reports, vol. 9, no. 1, p. 79, 2015.

[86] P. Lu, L. L. Jones, and M. H. Tuszynski, “BDNF-expressing marrow stromal cells support extensive axonal growth at sites of spinal cord injury," Experimental Neurology, vol. 191, no. 2, pp. 344-360, 2005.

[87] S. K. Oh, K. H. Choi, J. Y. Yoo, D. Y. Kim, S. J. Kim, and S. R. Jeon, "A phase III clinical trial showing limited efficacy of autologous mesenchymal stem cell therapy for spinal cord injury," Neurosurgery, vol. 78, no. 3, pp. 436-447, 2016. 
[88] R. Pal, N. K. Venkataramana, A. Bansal et al., "Ex vivoexpanded autologous bone marrow-derived mesenchymal stromal cells in human spinal cord injury/paraplegia: a pilot clinical study," Cytotherapy, vol. 11, no. 7, pp. 897-911, 2009.

[89] U. G. Thakkar, A. V. Vanikar, H. L. Trivedi et al., "Infusion of autologous adipose tissue derived neuronal differentiated mesenchymal stem cells and hematopoietic stem cells in post-traumatic paraplegia offers a viable therapeutic approach," Advanced Biomedical Research, vol. 5, no. 1, p. 51, 2016.

[90] J. Vaquero, M. Zurita, M. A. Rico et al., "Repeated subarachnoid administrations of autologous mesenchymal stromal cells supported in autologous plasma improve quality of life in patients suffering incomplete spinal cord injury," Cytother$a p y$, vol. 19, no. 3, pp. 349-359, 2017.

[91] C. G. Gerin, I. C. Madueke, T. Perkins et al., "Combination strategies for repair, plasticity, and regeneration using regulation of gene expression during the chronic phase after spinal cord injury," Synapse, vol. 65, no. 12, pp. 1255-1281, 2011.

[92] Y. C. Kim, Y. H. Kim, J. W. Kim, and K. Y. Ha, “Transplantation of mesenchymal stem cells for acute spinal cord injury in rats: comparative study between Intralesional injection and scaffold based transplantation," Journal of Korean Medical Science, vol. 31, no. 9, pp. 1373-1382, 2016.

[93] R. C. Assuncao-Silva, E. D. Gomes, N. Sousa, N. A. Silva, and A. J. Salgado, "Hydrogels and cell based therapies in spinal cord injury regeneration," Stem Cells International, vol. 2015, Article ID 948040, 24 pages, 2015.

[94] C. S. Ahuja and M. Fehlings, "Concise review: bridging the gap: novel neuroregenerative and neuroprotective strategies in spinal cord injury," Stem Cells Translational Medicine, vol. 5, no. 7, pp. 914-924, 2016.

[95] S. Yao, X. Liu, S. Yu et al., "Co-effects of matrix low elasticity and aligned topography on stem cell neurogenic differentiation and rapid neurite outgrowth," Nanoscale, vol. 8, no. 19, pp. 10252-10265, 2016.

[96] I. Caron, F. Rossi, S. Papa et al., "A new three dimensional biomimetic hydrogel to deliver factors secreted by human mesenchymal stem cells in spinal cord injury," Biomaterials, vol. 75, pp. 135-147, 2016.

[97] F. Faghihi, E. Mirzaei, J. Ai et al., "Differentiation potential of human chorion-derived mesenchymal stem cells into motor neuron-like cells in two- and three-dimensional culture systems," Molecular Neurobiology, vol. 53, no. 3, pp. 1862$1872,2016$.

[98] J. Qu, D. Wang, H. Wang et al., "Electrospun silk fibroin nanofibers in different diameters support neurite outgrowth and promote astrocyte migration," Journal of Biomedical Materials Research. Part a, vol. 101, no. 9, pp. 2667-2678, 2013.

[99] J. Wang, R. Ye, Y. Wei et al., "The effects of electrospun TSF nanofiber diameter and alignment on neuronal differentiation of human embryonic stem cells," Journal of Biomedical Materials Research. Part a, vol. 100, no. 3, pp. 632-645, 2012.

[100] D. Tukmachev, S. Forostyak, Z. Koci et al., "Injectable extracellular matrix hydrogels as scaffolds for spinal cord injury repair," Tissue Engineering. Part a, vol. 22, no. 3-4, pp. 306317, 2016.

[101] M. I. Gunther, N. Weidner, R. Muller, and A. Blesch, "Cellseeded alginate hydrogel scaffolds promote directed linear axonal regeneration in the injured rat spinal cord," Acta Biomaterialia, vol. 27, pp. 140-150, 2015.
[102] A. J. Hyatt, D. Wang, C. van Oterendorp, J. W. Fawcett, and K. R. Martin, "Mesenchymal stromal cells integrate and form longitudinally-aligned layers when delivered to injured spinal cord via a novel fibrin scaffold," Neuroscience Letters, vol. 569, pp. 12-17, 2014.

[103] X. Li, C. Yang, L. Li et al., "A therapeutic strategy for spinal cord defect: human dental follicle cells combined with aligned PCL/PLGA electrospun material," BioMed Research International, vol. 2015, Article ID 197183, 12 pages, 2015.

[104] Q. Zhang, S. Yan, R. You et al., "Multichannel silk protein/ laminin grafts for spinal cord injury repair," Journal of Biomedical Materials Research. Part $a$, vol. 104, no. 12, pp. 3045-3057, 2016.

[105] A. E. Ropper, D. K. Thakor, I. Han et al., "Defining recovery neurobiology of injured spinal cord by synthetic matrixassisted hMSC implantation," Proceedings of the National Academy of Sciences of the United States of America, vol. 114, no. 5, pp. E820-E829, 2017.

[106] D. Sun, X. Zhuang, S. Zhang et al., "Exosomes are endogenous nanoparticles that can deliver biological information between cells," Advanced Drug Delivery Reviews, vol. 65, no. 3, pp. 342-347, 2013.

[107] Y. Wang, L. Zhang, Y. Li et al., "Exosomes/microvesicles from induced pluripotent stem cells deliver cardioprotective miRNAs and prevent cardiomyocyte apoptosis in the ischemic myocardium," International Journal of Cardiology, vol. 192, pp. 61-69, 2015.

[108] T. Liu, X. Zhang, S. Gao et al., "Exosomal long noncoding RNA CRNDE-h as a novel serum-based biomarker for diagnosis and prognosis of colorectal cancer," Oncotarget, vol. 7, no. 51, pp. 85551-85563, 2016.

[109] M. Isin, E. Uysaler, E. Ozgur et al., "Exosomal lncRNA-p21 levels may help to distinguish prostate cancer from benign disease," Frontiers in Genetics, vol. 6, p. 168, 2015.

[110] T. S. Chen, R. C. Lai, M. M. Lee, A. B. Choo, C. N. Lee, and S. K. Lim, "Mesenchymal stem cell secretes microparticles enriched in pre-microRNAs," Nucleic Acids Research, vol. 38, no. 1, pp. 215-224, 2010.

[111] D. Pashoutan Sarvar, K. Shamsasenjan, and P. Akbarzadehlaleh, "Mesenchymal stem cell-derived exosomes: new opportunity in cell-free therapy," Advanced Pharmaceutical Bulletin, vol. 6, no. 3, pp. 293-299, 2016.

[112] M. Nakano, K. Nagaishi, N. Konari et al., "Bone marrowderived mesenchymal stem cells improve diabetes-induced cognitive impairment by exosome transfer into damaged neurons and astrocytes," Scientific Reports, vol. 6, p. 24805, 2016.

[113] Y. Zhang, M. Chopp, Y. Meng et al., "Effect of exosomes derived from multipluripotent mesenchymal stromal cells on functional recovery and neurovascular plasticity in rats after traumatic brain injury," Journal of Neurosurgery, vol. 122, no. 4, pp. 856-867, 2015.

[114] Y. Zhang, M. Chopp, X. S. Liu et al., "Exosomes derived from mesenchymal stromal cells promote axonal growth of cortical neurons," Molecular Neurobiology, vol. 54, no. 4, pp. 26592673, 2017.

[115] L. N. Novikova, M. Brohlin, P. J. Kingham, L. N. Novikov, and M. Wiberg, "Neuroprotective and growth-promoting effects of bone marrow stromal cells after cervical spinal cord injury in adult rats," Cytotherapy, vol. 13, no. 7, pp. 873-887, 2011. 
[116] B. I. Awad, M. A. Carmody, and M. P. Steinmetz, "Potential role of growth factors in the management of spinal cord injury," World Neurosurgery, vol. 83, no. 1, pp. 120-131, 2015.

[117] K. Arai, Y. Harada, H. Tomiyama et al., "Evaluation of the survival of bone marrow-derived mononuclear cells and the growth factors produced upon intramedullary transplantation in rat models of acute spinal cord injury," Research in Veterinary Science, vol. 107, pp. 88-94, 2016.

[118] S. R. Jeong, M. J. Kwon, H. G. Lee et al., "Hepatocyte growth factor reduces astrocytic scar formation and promotes axonal growth beyond glial scars after spinal cord injury," Experimental Neurology, vol. 233, no. 1, pp. 312-322, 2012.

[119] A. Ebens, K. Brose, E. D. Leonardo et al., "Hepatocyte growth factor/scatter factor is an axonal chemoattractant and a neurotrophic factor for spinal motor neurons," Neuron, vol. 17, no. 6, pp. 1157-1172, 1996.

[120] K. Kitamura, A. Iwanami, M. Nakamura et al., "Hepatocyte growth factor promotes endogenous repair and functional recovery after spinal cord injury," Journal of Neuroscience Research, vol. 85, no. 11, pp. 2332-2342, 2007.

[121] L. M. Urdzikova, J. Ruzicka, M. LaBagnara et al., "Human mesenchymal stem cells modulate inflammatory cytokines after spinal cord injury in rat," International Journal of Molecular Sciences, vol. 15, no. 7, pp. 11275-11293, 2014.

[122] C. Li, X. Chen, S. Qiao et al., "Effects of Wharton's jelly cells of the human umbilical cord on acute spinal cord injury in rats, and expression of interleukin- $1 \beta$ and nerve growth factor in spinal cord tissues," Artificial Cells, Nanomedicine, and Biotechnology, vol. 44, no. 5, pp. 1254-1258, 2016.

[123] D. Han, C. Wu, Q. Xiong, L. Zhou, and Y. Tian, “Anti-inflammatory mechanism of bone marrow mesenchymal stem cell transplantation in rat model of spinal cord injury," Cell Biochemistry and Biophysics, vol. 71, no. 3, pp. 1341-1347, 2015.

[124] T. B. Ribeiro, A. S. Duarte, A. L. Longhini et al., "Neuroprotection and immunomodulation by xenografted human mesenchymal stem cells following spinal cord ventral root avulsion," Scientific Reports, vol. 5, no. 1, p. 16167, 2015.

[125] K. K. Veeravalli, V. R. Dasari, A. J. Tsung et al., "Human umbilical cord blood stem cells upregulate matrix metalloproteinase-2 in rats after spinal cord injury," Neurobiology of Disease, vol. 36, no. 1, pp. 200-212, 2009.

[126] X. Zeng, Y. H. Ma, Y. F. Chen et al., "Autocrine fibronectin from differentiating mesenchymal stem cells induces the neurite elongation in vitro and promotes nerve fiber regeneration in transected spinal cord injury," Journal of Biomedical Materials Research. Part a, vol. 104, no. 8, pp. 1902-1911, 2016.

[127] K. Menezes, M. A. Nascimento, J. P. Goncalves et al., "Human mesenchymal cells from adipose tissue deposit laminin and promote regeneration of injured spinal cord in rats," PloS One, vol. 9, no. 5, article e96020, 2014.

[128] N. B. Isele, H. S. Lee, S. Landshamer et al., "Bone marrow stromal cells mediate protection through stimulation of PI3-K/Akt and MAPK signaling in neurons," Neurochemistry International, vol. 50, no. 1, pp. 243-250, 2007.

[129] Y. Wang, H. Liu, and H. Ma, "Intrathecally transplanting mesenchymal stem cells (MSCs) activates ERK1/2 in spinal cords of ischemia-reperfusion injury rats and improves nerve function," Medical Science Monitor : International Medical Journal of Experimental and Clinical Research, vol. 22, pp. 1472-1479, 2016.
[130] R. Zhang, H. Chen, Z. Zheng, Q. Liu, and L. Xu, "Umbilical cord-derived mesenchymal stem cell therapy for neurological disorders via inhibition of mitogen-activated protein kinase pathway-mediated apoptosis," Molecular Medicine Reports, vol. 11, no. 3, pp. 1807-1812, 2015.

[131] H. L. Tsai, W. P. Deng, W. F. Lai et al., "Wnts enhance neurotrophin-induced neuronal differentiation in adult bone-marrow-derived mesenchymal stem cells via canonical and noncanonical signaling pathways," PloS One, vol. 9, no. 8, article e104937, 2014.

[132] C. M. Fernandez-Martos, C. Gonzalez-Fernandez, P. Gonzalez, A. Maqueda, E. Arenas, and F. J. Rodriguez, "Differential expression of Wnts after spinal cord contusion injury in adult rats," PloS One, vol. 6, no. 11, article e27000, 2011.

[133] L. K. Briona, F. E. Poulain, C. Mosimann, and R. I. Dorsky, "Wnt/b-catenin signaling is required for radial glial neurogenesis following spinal cord injury," Developmental Biology, vol. 403, no. 1, pp. 15-21, 2015. 

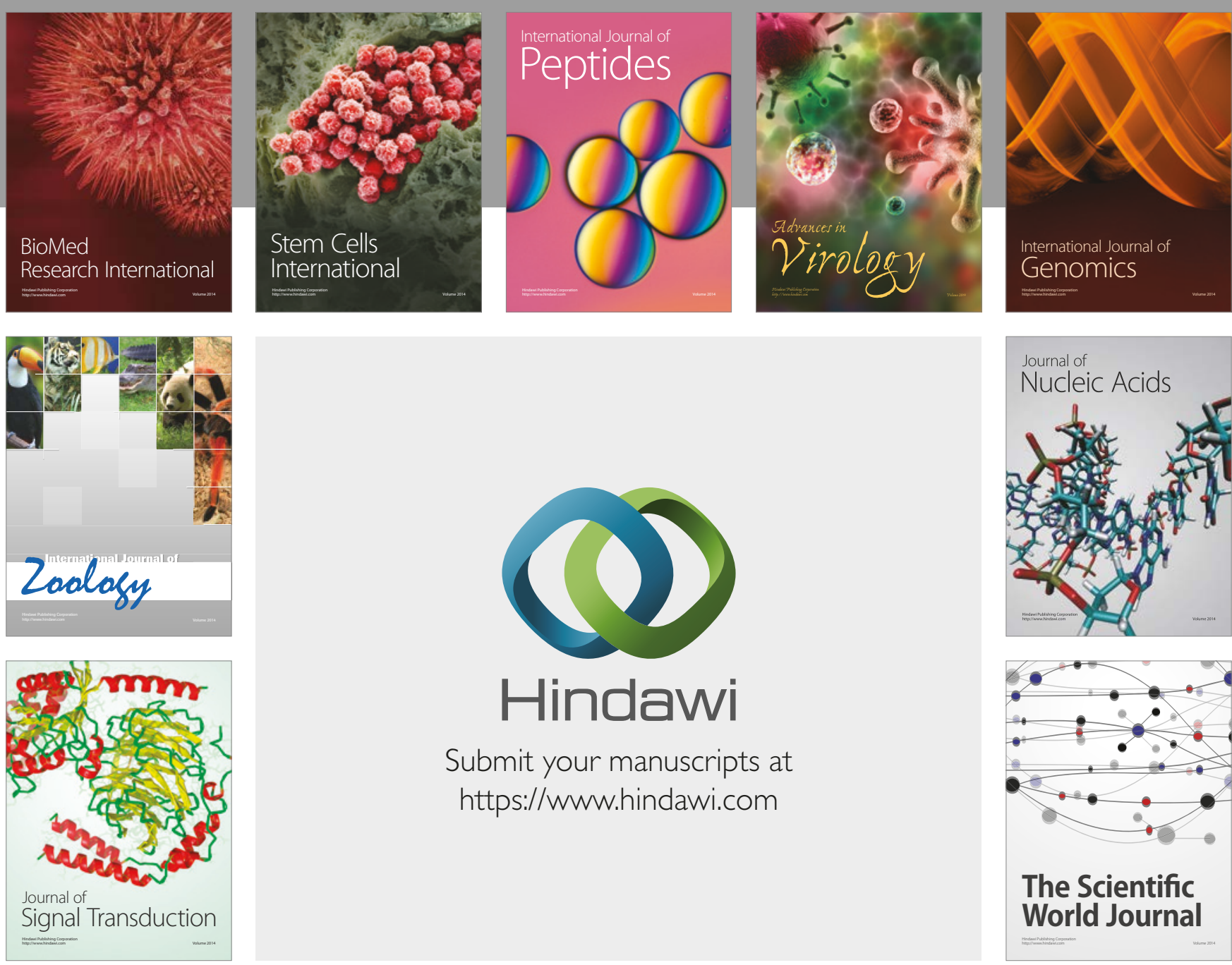

Submit your manuscripts at

https://www.hindawi.com
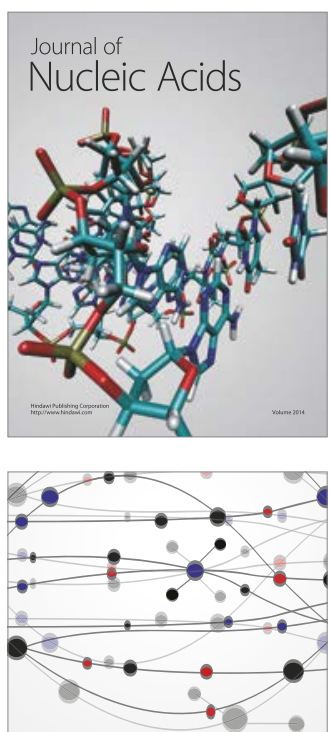

The Scientific World Journal

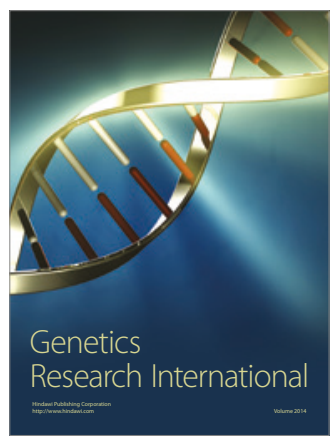

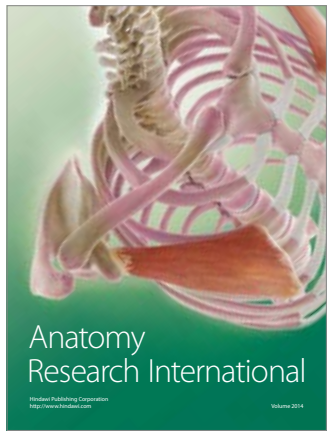

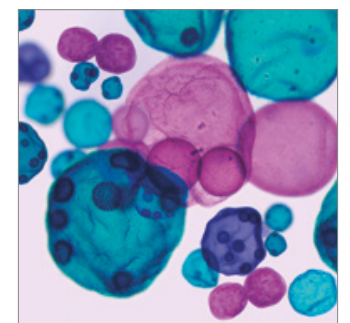

International Journal of Microbiology
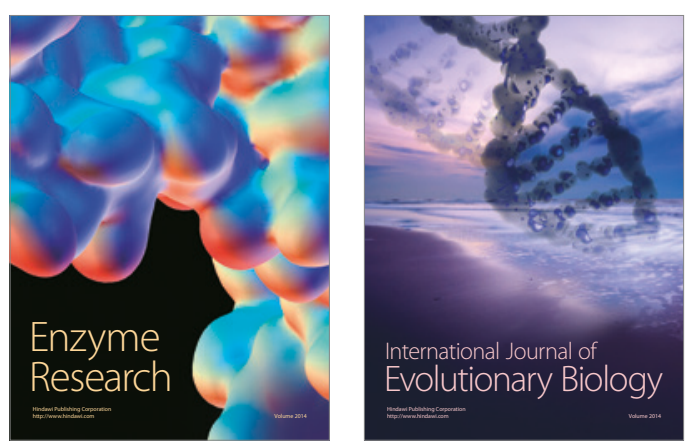
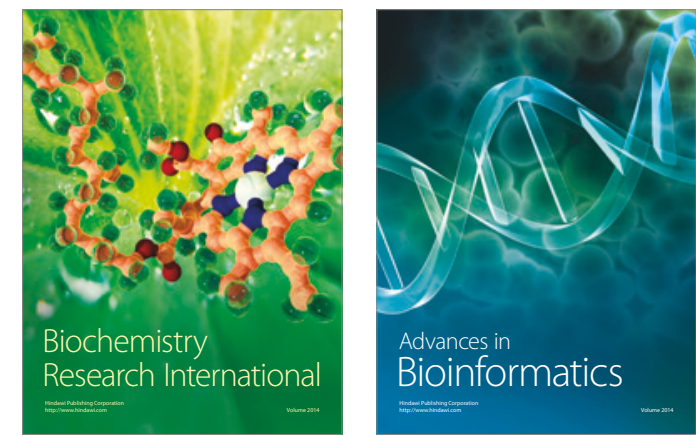

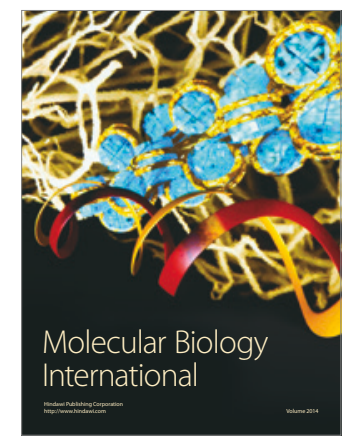

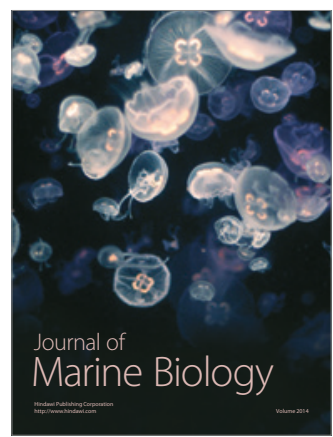

